\title{
MULTI-DIMENSIONAL HARDY TYPE INEQUALITIES IN HÖLDER SPACES
}

\section{Evgeniya Burtseva, Staffan Lundberg, LARs-Erik Persson and NATASHA SAMKO}

Abstract. Most Hardy type inequalities concern boundedness of the Hardy type operators in Lebesgue spaces. In this paper we prove some new multi-dimensional Hardy type inequalities in Hölder spaces.

Mathematics subject classification (2010): 46E15, 26D15, 47B38.

Keywords and phrases: Inequalities, Hardy type inequalities, Hölder spaces, Hardy type operators, boundedness, compactification.

\section{REFERENCES}

[1] E. Burtseva And N. Samko, Weighted Adams type theorem for the Riesz fractional integral in generalized Morrey space, Fract. Calc. Appl. Anal. 19 (4): 954-972, 2016.

[2] G. H. HARDY, Notes on some points in the integral calculus, LX. An inequality between integrals, Messenger of Math. 54: 150-156, 1925.

[3] G. H. HARdy, Notes on some points in the integral calculus, LXIV, Messenger of Math. 57: 12-16, 1928.

[4] G. H. Hardy, J. E. Littlewood, and G. Polya, Inequalities, Cambridge Univ. Press, 1934.

[5] V. Kokilashvili, A. Meskhi, And L.E. Pers Son, Weighted Norm Inequalities for Integral Transforms with Product Weights, Nova Scientific Publishers, Inc., New York, 2010.

[6] A. Kufner, L. Maligranda, And L.E. Persson, The Hardy Inequality - About its History and Some Related Results, Vydavatelsky Servis Publishing House, Pilsen, 2007.

[7] A. Kufner, L.E. Persson, And N. Samko, Weighted Inequalities of Hardy Type, second edition, World Scientific Publishing Co. Inc., River Edge, NY, 2017.

[8] L. LeINDLER, A note on embedding of classes $H^{\omega}$, Analysis Mathematica 27: 71-76, 2001.

[9] D. LuKKASSEn, L. E. PERSSON, AND N. SAMKO, Hardy type operators in local vanishing Morrey spaces on fractal sets, Fract. Calc. Appl. Anal. 18 (5): 1252-1276, 2015.

[10] S. LUNDBERG AND N. S AMKO, On some hyperbolic type equations and weighted anisotropic Hardy operators, Math. Methods Appl. Sci, doi :10.1002/mma.4062, 2016.

[11] S. M. NiKOL's KI, Priblizhenie funktsi mnogikh peremennykh i teoremy vlozheniya, (Russian) [Approximation of functions of several variables and imbedding theorems] second edition, revised and supplemented, Nauka, Moscow, 1977.

[12] L. E. Persson And N. SAmKo, Some remarks and new developments concerning Hardy-type inequalities, Rend. Circ. Mat. Palermo, serie I, 82 (4): 1-29, 2010.

[13] L. E. PERSSON AND N. SAMKO, Weighted Hardy and potential operators in the generalized Morrey spaces, J. Math. Anal. Appl. 377: 792-806, 2011.

[14] N. S AmKo, On compactness of Integral Operators with a Generalized Weak Singularity in Weighted Spaces of Continuous Functions with a Given Continuity Modulus, Proc. A. Razmadze Math. Inst. 136: 91-113, 2004.

[15] N. Samко, Weighted Hardy and singular operators in Morrey spaces, J. Math. Anal. Appl. 350: 56-72, 2009.

[16] N. S Aмко, Weighted Hardy operators in the local generalized vanishing Morrey spaces, Positivity 17 (3): 683-706, 2013. 
[17] S. G. Samko, A. A. Kilbas, And O. I. Marichev, Fractional Integrals and Derivatives, Theory and Applications, London-New York: Gordon \& Breach, Sci. Publ., (Russian edition - Fractional Integrals and Derivatives and some of their Applications, Minsk: Nauka i Tekhnika, 1987.), 1993, 1012 pages.

[18] S. B. STEChKin, On the order of the best approximations of continuous functions, Izv. Akad. Nauk SSSR Ser. Mat. 15 (3): 219-242, 1951.

[19] C. TANG AND R. ZHOU, Boundedness of weighted Hardy operator and its adjoint on Triebel-Lizorkintype spaces, J. Funct. Spaces Appl. 2012, Article ID 610649. 